\title{
COMMENTARY
}

\section{Sepsis-related stress response: known knowns, known unknowns, and unknown unknowns}

\author{
Jinmin Peng and Bin Du* \\ See related research by Lesur et al., http://ccforum.com/content/14/4/R131
}

\begin{abstract}
The hypothalamic-pituitary-adrenal (HPA) axis response in sepsis remains to be elucidated. Apart from corticotropin-releasing hormone, adrenocorticotropic hormone, and cortisol, many other neuroendocrine factors participate in the regulation of HPA stress response. The HPA response to acute and chronic illness exerts a biphasic profile. Tissue corticosteroid resistance may also play an important role. All of these add to the complexity of the concept of 'relative adrenal insufficiency' and may account for the difficulty of clinical diagnosis and for the conflicting results of corticosteroid replacement therapy in severe sepsis/ septic shock. The study by Lesur and colleagues expands our understanding of the mechanism, and further study of HPA stress response is warranted.
\end{abstract}

In this issue of Critical Care, Lesur and colleagues [1] report the differential profile of stress response in septic and non-septic patients. Adrenocorticotropic hormone (ACTH) and $\mathrm{ACTH} /$ cortisol ratio were lower whereas baseline cortisol, procalcitonin (PCT), and stromal cellderived factor-1-alpha (SDF-1 $\alpha$ ) were higher in septic patients than in non-septic patients. Furthermore, a probability score incorporating ACTH, cortisol, and PCT by multivariate logistic regression analysis predicted sepsis better than sepsis score or PCT did [1].

The response of hypothalamic-pituitary-adrenal (HPA) axis to the sustained stress of severe illness has been the focus of many studies in recent years. In healthy subjects, cortisol secretion by adrenal cortex is regulated by ACTH secretion by the pituitary, which in turn is regulated primarily by hypothalamic secretion of corticotropinreleasing hormone $(\mathrm{CRH})$, whereas cortisol inhibits both

*Correspondence: dubin98@gmail.com

Medical Intensive Care Unit, Peking Union Medical College Hospital, Peking Union Medical College and Chinese Academy of Medical Sciences, 1 Shuai Fu Yuan, Beijing 100730, People's Republic of China
$\mathrm{ACTH}$ and $\mathrm{CRH}$ production through a negative feedback [2-4].

However, HPA stress response during sepsis is much more complex and is poorly defined. Plasma cortisol levels may be low, normal, or high in sepsis [2,5] but nonetheless inadequate to control the inflammatory response and meet the elevated metabolic demand [5]. This effect is termed relative adrenal insufficiency (RAI), also known as critical illness-related corticosteroid insufficiency (CIRCI) $[2,3,6]$.

Other factors are involved in the HPA stress response during sepsis [6,7]. In rodent models, arginine vasopressin (AVP) was shown to increase endogenous adrenal ACTH secretion [7]. Apelin, a neuropeptide originating from paraventricular and supraopitc nuclei, acts on HPA axis regulation by releasing $\mathrm{CRH}$ and $\mathrm{ACTH}$ and by reducing AVP [7]. Copeptin, a 39-amino acid glycopeptide, makes up the pre-pro-vasopressin molecule together with neurophysin II and AVP and serves as a surrogate marker to assess AVP plasma concentrations in septic shock [8]. In normal rats, the chemokine SDF-1 $\alpha$ and its receptor colocalize with AVP in magnocellular neurosecreatory neurons, resulting in an inhibition of AVP-induced release [9].

Real life is even more complex. The HPA may display a biphasic pattern during the course of a critical illness $[4,10]$. The dissociation of ACTH and cortisol levels in late phase (lasting many days to weeks), which is different from that of the acute phase (hours to a few days) of an illness, indicates that alternative pathways not mediated by ACTH are involved. Moreover, androgens produced by zona reticularis are affected in sepsis or CIRCI. Limited clinical studies prove that the dehydroepiandrosterone (DHEA) level is very low in septic shock, whereas its sulphate and the cortisol/DHEA ratio might be prognostic markers and signs of exhausted adrenal reserve in critical illness [11]. Tissue resistance to corticosteroid action may also play an important role in sepsis [6] and can be caused by either defects in the corticosteroid receptor or postreceptor alterations and may not be defined accurately based on plasma cortisol levels [3,4]. 
Despite the uncertainty of the definition and diagnostic criteria, clinical studies show that patients with RAI are at a significantly higher risk of hospital mortality [12] and this has been the driver for corticosteroid replacement therapy in severe sepsis/septic shock [2-4]. However, clinical trials with stress-dose corticosteroid show conflicting results $[13,14]$. This is not surprising upon review of the aforementioned complexity and unknowns of HPA stress response. Furthermore, it must be acknowledged that the decision to treat with stress-dose corticosteroids is based on clinical criteria rather than on the inconclusive results of adrenal function tests.

The limitations of the study by Lesur and colleagues [1] should be considered. The dissociation of ACTH and cortisol levels observed in the study is more compatible with neuroendocrine characteristics of prolonged critical illness [4], although the authors claimed to include patients within the first 24 hours of admission [1]. The clinical significance of the predictive model is hindered by the unavailability of ACTH or cortisol measurements at the bedside and by the fact that the predictive value of sepsis score or PCT has not been consistently validated in clinical trials [15].

Despite all of these limitations, the study by Lesur and colleagues undoubtedly expands our understanding of the complex neuroendocrine network regulating HPA stress response in human sepsis. We believe that further investigation into the mechanism is warranted before we plan a successful strategy for corticosteroid replacement in sepsis.

\section{Abbreviations}

ACTH, adrenocorticotropic hormone; AVP, arginine vasopressin; CIRCl, critical illness-related corticosteroid insufficiency; $\mathrm{CRH}$, corticotropin-releasing hormone; DHEA, dehydroepiandrosterone; HPA, hypothalamic-pituitaryadrenal; PCT, procalcitonin; RAl, relative adrenal insufficiency; SDF-1a, stromal cell-derived factor-1-alpha.

\section{Competing interests}

The authors declare that they have no competing interests.

Published: 19 July 2010
References

1. Lesur O, Roussy JF, Chagnon F, Gallo-Payet N, Dumaine R, Sarret P, Chraibi A, Chouinard L, Hogue B: Proven infection-related sepsis induces a differential stress response early after ICU admission. Crit Care 2010, 14:R131.

2. Cooper MS, Stewart PM: Corticosteroid insufficiency in acutely ill patients. N Engl J Med 2003, 348:727-734.

3. Marik P: Critical illness-related corticosteroid insufficiency. Chest 2009, 135:181-193.

4. Arafah BM: Hypothalamic pituitary adrenal function during critical illness: limitations of current assessment methods. J Clin Endocrinol Metab 2006, 91:3725-3745.

5. Annetta MG, Maviglia R, Proietti R, Antonelli M: Use of corticosteroids in critically ill septic patients: a review of mechanisms of adrenal insufficiency in sepsis and treatment. Current Drug Targets 2009, 10:887-894.

6. Marik P, Pastores SM, Annane D, Meduri GU, Sprung CL, Arlt W, Keh D, Briegel J, Beishuizen A, Dimopoulou I, Tsagarakis S, Singer M, Chrousos GP, Zaloga G, Bokhari F, Vogeser M: Recommendations for the diagnosis and management of corticosteroid insufficiency in critically ill adult patients: consensus statements from an international task force by the American College of Critical Care Medicine. Crit Care Med 2008, 36:1937-1949.

7. Maxime V, Lesur O, Annane D: Adrenal insufficiency in septic shock. Clin Chest Med 2009, 30:17-27.

8. Katan M, Muller B, Christ-Crain M: Copeptin: a new and promising diagnostic and prognostic marker. Crit Care 2008, 12:117.

9. Callewaere C, Banisadr G, Desarmenien MG, Mechighel P, Kitabgi P, Rostene WH, Parsadaniantz SM: The chemokine SDF-1/CXCL12 modulates the firing pattern of vasopressin neurons and counteracts induced vasopressin release through CXCR4. Proc Natl Acad Sci U S A 2006, 103:8221-8226.

10. Mesotten D, Vanhorebeek I, Van den Berghe G: The altered adrenal axis and treatment with glucocorticoids during critical illness. Nature Clin Pract Endocrinol Metab 2008, 4:496-505.

11. Beishuizen A, Thijs LG, Vermes I: Decreased levels of dehydroepiandrosterone sulphate in severe critical illness: a sign of exhausted adrenal reserve? Crit Care 2002, 6:434-438.

12. Annane D, Sebille V, Troche G, Raphael JC, Gajdos P, Bellissant E: A 3-level prognostic classification in septic shock based on cortisol levels and cortisol response to corticotropin. JAMA 2000, 283:1038-1045.

13. Annane D, Sébille V, Charpentier C, Bollaert PE, François B, Korach JM, Capellier G, Cohen Y, Azoulay E, Troché G, Chaumet-Riffaud P, Bellissant E: Effect of treatment with low doses of hydrocortisone and fludrocortisones on mortality in patients with septic shock. JAMA 2002, 288:862-871.

14. Sprung $C L$, Annane D, Keh D, Moreno R, Singer M, Freivogel $K$, Weiss YG, Benbenishty J, Kalenka A, Forst H, Laterre PF, Reinhart K, Cuthbertson BH, Payen D, Briegel J, CORICUS Study Group: Hydrocortisone therapy for patients with septic shock. N Engl J Med 2008, 358:111-124.

15. Vincent JL, Mercan D: Dear Sirs, what is your PCT? Intensive Care Med 2000 , 26:1170-1171.

doi:10.1186/cc9103

Cite this article as: Peng J, Du B: Sepsis-related stress response: known

knowns, known unknowns, and unknown unknowns. Critical Care 2010, 14:179. 